\title{
@ (1) Hepatitis E virus in blood components: a prevalence and transmission study in southeast England
}

Patricia E Hewitt, Samreen Ijaz, Su R Brailsford, Rachel Brett, Steven Dicks, Becky Haywood, Iain T R Kennedy, Alan Kitchen, Poorvi Patel, John Poh, Katherine Russell, Kate I Tettmar, Joanne Tossell, Ines Ushiro-Lumb, Richard S Tedder

Lancet 2014; 384: 1766-73

Published Online July 28,2014 http://dx.doi.org/10.1016/ S0140-6736(14)61034-5

See Comment page 1729

Transfusion Microbiology, National Health Service Blood and Transplant, London, UK (PE Hewitt FRCPath,

$S R$ Brailsford PhD, R Brett BSC,

$S$ Dicks MSc, A Kitchen PhD, P Patel MSc,

K I Tettmar MBA, J Tossell RN, I Ushiro-Lumb FRCPath,

Prof R S Tedder FR(Path); Blood

Borne Virus Unit, Virus

Reference Department,

Microbiology Services

(S ljaz PhD, S Dicks,

B Haywood BSc, P Patel,

J Poh PhD, K I Tettmar,

IUshiro-Lumb, Prof R STedder) and Centre for Infectious Disease Surveillance and

Control (S R Brailsford,

IT R Kennedy MFPH,

K Russell MFPH), Public Health England, London, UK; and University College London, Gower Street, London, UK (Prof R S Tedder)

Correspondence to:

Prof Richard STedder, Blood Borne Virus Unit, Virus Reference

Department, Microbiology Services, Public Health England,

London NW9 5EQ, UK richard.tedder@phe.gov.uk

\section{Summary}

Background The prevalence of hepatitis E virus (HEV) genotype 3 infections in the English population (including blood donors) is unknown, but is probably widespread, and the virus has been detected in pooled plasma products. HEV-infected donors have been retrospectively identified through investigation of reported cases of possible transfusion-transmitted hepatitis E. The frequency of HEV transmission by transfusion and its outcome remains unknown. We report the prevalence of HEV RNA in blood donations, the transmission of the virus through a range of blood components, and describe the resulting morbidity in the recipients.

Methods From Oct 8, 2012, to Sept 30, 2013, 225000 blood donations that were collected in southeast England were screened retrospectively for HEV RNA. Donations containing HEV were characterised by use of serology and genomic phylogeny. Recipients, who received any blood components from these donations, were identified and the outcome of exposure was ascertained.

Findings 79 donors were viraemic with genotype $3 \mathrm{HEV}$, giving an RNA prevalence of one in 2848. Most viraemic donors were seronegative at the time of donation. The 79 donations had been used to prepare 129 blood components, 62 of which had been transfused before identification of the infected donation. Follow-up of 43 recipients showed $18(42 \%)$ had evidence of infection. Absence of detectable antibody and high viral load in the donation rendered infection more likely. Recipient immunosuppression delayed or prevented seroconversion and extended the duration of viraemia. Three recipients cleared longstanding infection after intervention with ribavirin or alteration in immunosuppressive therapy. Ten recipients developed prolonged or persistent infection. Transaminitis was common, but short-term morbidity was rare; only one recipient developed apparent but clinically mild post-transfusion hepatitis.

Interpretation Our findings suggest that HEV genotype 3 infections are widespread in the English population and in blood donors. Transfusion-transmitted infections rarely caused acute morbidity, but in some immunosuppressed patients became persistent. Although at present blood donations are not screened, an agreed policy is needed for the identification of patients with persistent $\mathrm{HEV}$ infection, irrespective of origin, so that they can be offered antiviral therapy.

Funding Public Health England and National Health Service Blood and Transplant.

Copyright (C) Hewitt et al. Open Access article distributed under the terms of CC BY-NC-ND.

\section{Introduction}

Hepatitis E was first recognised as a clinical disease in 1978 as an outbreak of epidemic non-A, non-B hepatitis in Kashmir. ${ }^{1}$ In 1990, faecal extracts from cases in a Russian military camp were shown to be infectious orally in people and domestic pigs, ${ }^{2,3}$ with the infective agent hepatitis $\mathrm{E}$ virus (HEV) being partly sequenced the same year. ${ }^{4}$ There are four HEV genotypes- 1 and 2 (human viruses), and 3 and 4 (animal viruses) that infect human beings zoonotically. The results of a recent population-based seroprevalence study in England and Wales suggested that the prevalence of infection is more common than would be expected from an imported infection and that $25 \%$ of adults in the sixth and seventh decades of life are seropositive.

In the UK, the numbers of cases of hepatitis $E$ have increased every year since $2010^{6}$ and this increase is associated with the emergence of a viral phylotype not previously seen. HEV is now the most common infective cause of acute enterically transmitted viral hepatitis and is detected in people who have not travelled outside the UK. ' The association between hepatitis $\mathrm{E}$ and consumption of processed pork products makes hepatitis E a likely zoonosis in the $\mathrm{UK}^{8}$ and other countries where viral sequencing has implicated food containing animal products from pigs, ${ }^{9}$ boar, ${ }^{10}$ and deer. ${ }^{11}$

The first transmission in the UK of HEV from a blood component reported in $2006^{12}$ was identified retrospectively in the recipients of blood components from a donor diagnosed with hepatitis E 24 days after donation. Post-transfusion hepatitis E seems unusual and since the first report eight post-transfusion HEV enquiries (two in 2013, five in 2012, and one in 2011) have been notified to the National Health Service Blood and Transplant (NHSBT). Only the two most recent cases 
were confirmed to be linked to components from an infected donor. HEV RNA in UK plasma pools ${ }^{13,14}$ and serological evidence of recent HEV infection in donors ${ }^{15}$ have also been documented, indicating a turnover of HEV in donors, but neither finding provides a measure of the prevalence of viraemia. Intercurrent immuno suppression, common in component recipients, can delay viral clearance and lead to viral persistence in patients with solid organ transplant ${ }^{16}$ and HIV infection. ${ }^{17,18}$ These findings have raised the question of whether the hazard from HEV infection in donors ought to be defined. We report here the prevalence of HEV RNA in blood donors, the transmission of HEV by a range of components, and we describe the resulting morbidity in recipients.

\section{Methods}

This study and related protocols were presented to the London Bridge Research Ethics Committee (reference 12/LO/0987) and approval was received in September, 2012. An overarching data monitoring committee maintained an independent continuous review of the progress of the study. A study steering group, reporting to the data monitoring committee, reviewed all aspects of the study on a weekly basis. Identification and clinical follow-up of exposed recipients were coordinated by the NHSBT in accordance with existing protocols for the discharge of the duty of care to recipients of components carrying previously unidentified risks.

From Oct 8, 2012, to Sept 30, 2013, plasma samples from individual donations collected in the South East

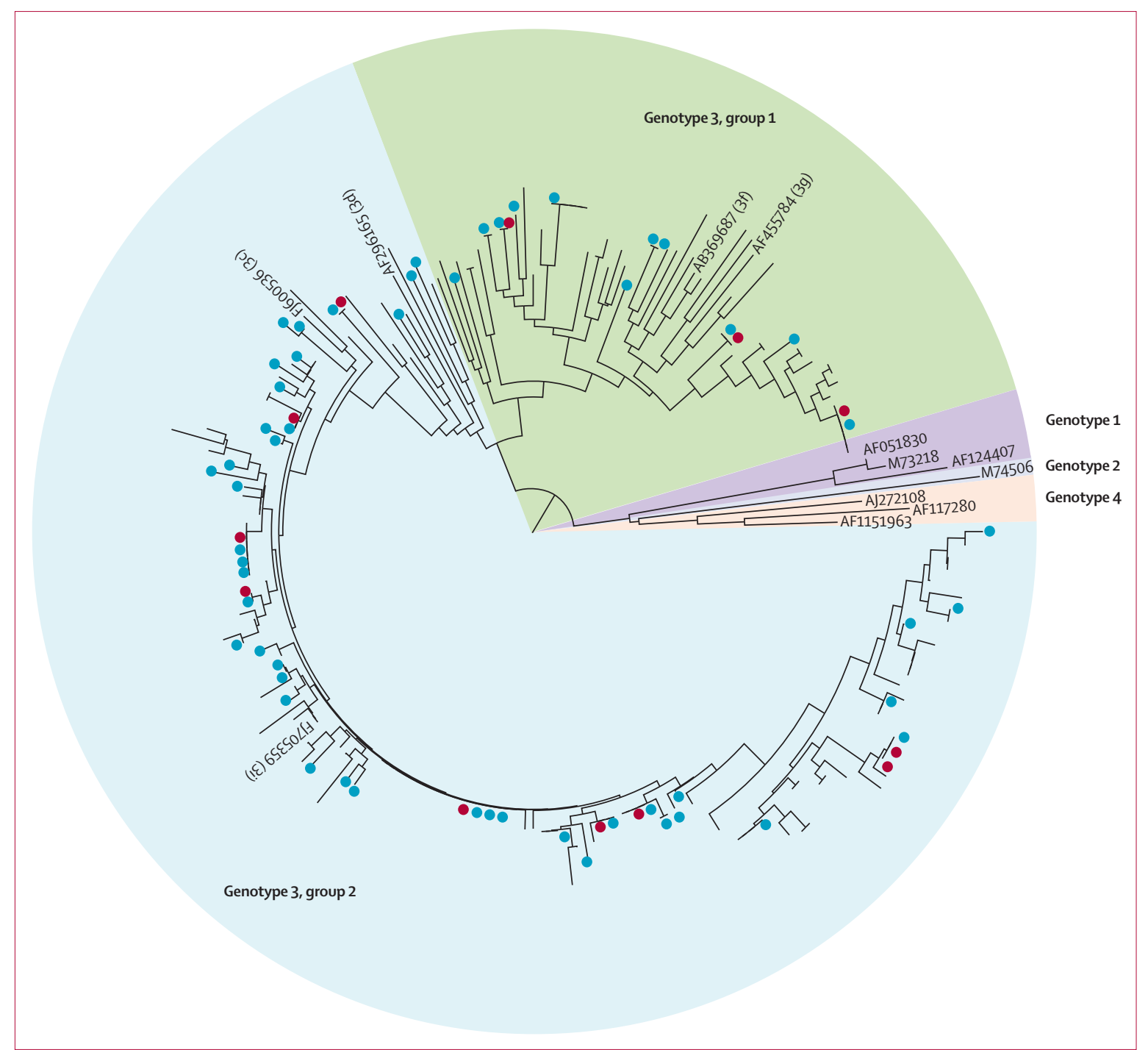

Figure 1: Phylogenetic tree based on partial of open reading frame 2 nucleotide sequences from cases of HEV infection The genotype 3 sequences are from acute hepatitis $\mathrm{E}$ cases diagnosed in England and Wales, UK, during the study period and are shown as unlabelled branches. Sequences from $54 \mathrm{HEV}$-infected blood donors are shown as blue dots and $12 \mathrm{HEV}$-infected recipients are shown as red dots. Accession numbers for reference sequences are given. HEV=hepatitis E virus. 
of England from consenting donors were dispatched from NHSBT Filton, Bristol, to NHSBT Colindale, London, UK, where minipools of 24 donations, or fewer if a full 24 set was not available at the time of pooling, were assembled and extracted on the QiaSymphony (Qiagen, Crawley, UK; virus-specific cell-free protocol). At any point in time, staff and equipment limitations determined whether all sequential donations were taken for pooling or discarded. 9382 minipools were screened for HEV RNA during the study. HEV RNA was detected with an internally controlled RT-PCR ${ }^{19}$ (detection limit $22 \mathrm{IU} / \mathrm{mL}$ ). Briefly, extracted nucleic acid in $10 \mu \mathrm{L}$ was reverse transcribed in $25 \mu \mathrm{L}$ with Quantitect Probe rt-pcr (Qiagen, Crawley, UK) and then amplified through 45 cycles. Sample reactivity was ascribed an RNA value in $\mathrm{IU} / \mathrm{mL}$ by comparison with a standard curve of serial $\log _{10}$ dilutions in normal human plasma of a high titre sample of known potency in WHO international units. Reactive pools were resolved to individual donations that were then subjected to HEV RNA detection, quantification, phylogeny, and serology. Plasma RNA was amplified, sequenced, and subjected to phylogenetic analysis across part of the open reading frame 2 as previously described. ${ }^{5}$

HEV antibody was detected with the Wantai IgM and IgG detection assays (Fortress Diagnostics, Antrim, Northern Ireland, UK) in accordance with the manufacturer's instructions.

\begin{tabular}{|lccc|}
\hline & $\begin{array}{l}\text { Blood components associated } \\
\text { with HEV-viraemic donation }\end{array}$ & $\begin{array}{l}\text { Blood components } \\
\text { recalled or discarded }\end{array}$ & $\begin{array}{l}\text { Blood components } \\
\text { transfused }\end{array}$ \\
\hline Red blood cells & 71 & $48(68 \%)$ & $23(32 \%)$ \\
\hline Pooled platelets & 15 & $3(20 \%)$ & $12(80 \%)$ \\
Apheresis platelets & 24 & $1(4 \%)$ & $23(96 \%)$ \\
\hline Fresh frozen plasma & 12 & $9(75 \%)$ & $3(25 \%)$ \\
Cryoprecipitate & 6 & $6(100 \%)$ & 0 \\
Pooled granulocytes & 1 & 0 & $1(100 \%)$ \\
Total & 129 & $67(52 \%)$ & $62(48 \%)$ \\
Data are number or number (\%). & & \\
\hline \multicolumn{2}{l}{ Table 1: Blood components associated with viraemic donations } \\
\hline
\end{tabular}

\begin{tabular}{|lccc|}
\hline & $\begin{array}{l}\text { Recipients of blood } \\
\text { components }\end{array}$ & $\begin{array}{l}\text { Infected } \\
\text { recipients }\end{array}$ & $\begin{array}{l}\text { Uninfected } \\
\text { recipients }\end{array}$ \\
\hline Red blood cells & 16 & $4(25 \%)$ & $12(75 \%)$ \\
\hline Pooled platelets & 10 & $4(40 \%)$ & $6(60 \%)$ \\
Apheresis platelets & 14 & $7(50 \%)$ & $7(50 \%)$ \\
Fresh frozen plasma & 2 & $2(100 \%)$ & 0 \\
Pooled granulocytes & 1 & $1(100 \%)$ & 0 \\
Total & 43 & $18(42 \%)$ & $25(58 \%)$ \\
Data are number or number (\%). & \\
\hline $\begin{array}{l}\text { Table 2: Association between transfused blood components and } \\
\text { transmission of hepatitis E virus in 43 of 60 exposed patients in whom } \\
\text { follow-up was possible }\end{array}$ & \\
\hline
\end{tabular}

Unused blood components remaining in the NHSBT inventory were discarded and those already issued were recalled. A standard look back (ie, check) was initiated for all transfused components. The involved hospital transfusion team was asked to identify the recipient and the clinical team providing patient care. The clinical team (or family doctor if the recipient had been discharged) was advised of the possible exposure to HEV and sent information about HEV and a suggested recipient follow-up plan.

Through the attending clinician, clinical information on all of the recipients was sought. Where possible, blood samples were collected during the follow-up. Negative serology at 16 weeks post-transfusion and an absence of HEV RNA at any stage indicated the lack of transmission. The detection of plasma RNA at any stage or seroconversion or serological markers of recent infection indicated transmission. Any recipient with viraemia was monitored until HEV RNA clearance and the development of both IgG and IgM.

\section{Role of the funding source}

This study was jointly funded by Public Health England and the NHSBT. Pooling was done on NHSBT premises. Serology, molecular testing, and phylogenetic analysis were done on Public Health England premises. Donor records, including consent for testing, enrolment, and clinical data were maintained by the NHSBT. The corresponding author had full access to all the data in the study and had final responsibility for the decision to submit for publication.

\section{Results}

9382 minipools, comprising 225000 individual donations, were screened and 79 donations containing HEV RNA were identified, giving a prevalence of about one in 2848 donations $(0 \cdot 04 \%) .56$ (71\%) donors were seronegative (negative for anti-HEV IgM and anti-HEV IgG). The median viral load was $3900 \mathrm{IU} / \mathrm{mL}$ (range 50 to $2 \cdot 37 \times 10^{6}$ ) and was $0.5 \log _{10}$ higher in index donations that were antibody negative. 54 (68\%) of 79 donor samples could be genotyped and all had a genotype 3 virus (figure 1).

129 components were manufactured from 79 donations (table 1). Red cells comprised the largest number (71 [55\%]) followed by platelets (39 [30\%]), but, because of discard or recall, only $62(48 \%)$ components were given as transfusions to 60 recipients: one patient received two aliquots of an apheresis platelet donation, and another received two separate HEV-containing components (table 1). Platelets were the most commonly transfused virus-containing blood component (table 1).

Of the 60 patients given blood components from HEV-infected donors, one declined investigation. 16 patients were not available for follow-up: nine died soon after transfusion and before follow-up, five were terminally ill or incapacitated and therefore the initiation of HEV monitoring was thought to be inappropriate, and 


\begin{tabular}{|c|c|c|c|c|c|c|c|c|}
\hline & $\begin{array}{l}\text { Primary } \\
\text { diagnosis }\end{array}$ & $\begin{array}{l}\text { Inferred } \\
\text { immune } \\
\text { suppression }\end{array}$ & $\begin{array}{l}\text { Weeks to RNA } \\
\text { positivity }\end{array}$ & $\begin{array}{l}\text { Weeks to first } \\
\text { detection of } \\
\text { antibody }\end{array}$ & $\begin{array}{l}\text { Duration of } \\
\text { infection (weeks) }\end{array}$ & Viral clearance & $\begin{array}{l}\text { Alanine } \\
\text { aminotransferase } \\
(\mathrm{IU} / \mathrm{ml})\end{array}$ & Comment \\
\hline \multicolumn{9}{|l|}{ Patients 1-8 } \\
\hline Patient 1 & Cardiac surgery & None & $\begin{array}{l}\text { Marker not } \\
\text { detected }\end{array}$ & 8 & NA & Yes & Not raised & No illness \\
\hline Patient 2 & Cardiac surgery & None & $\begin{array}{l}\text { Marker not } \\
\text { detected }\end{array}$ & 14 & NA & Yes & No information & No illness \\
\hline Patient 3 & $\begin{array}{l}\text { Gastrointestinal } \\
\text { bleeding }\end{array}$ & None & $\begin{array}{l}\text { Marker not } \\
\text { detected }\end{array}$ & 6 & NA & Yes & Not raised & No illness \\
\hline Patient 4 & Cardiac surgery & None & 5 & 5 & 7 & Yes & 375 , week 7 & Mild jaundice \\
\hline Patient 5 & Sepsis & None & 2 & 10 & 10 & Yes & 42, week 2 & No information \\
\hline Patient 6 & $\begin{array}{l}\text { Myelodysplastic } \\
\text { syndrome }\end{array}$ & Mild & $\begin{array}{l}\text { Marker not } \\
\text { detected }\end{array}$ & 6 & NA & Yes & Not elevated & No illness \\
\hline Patient 7 & $\begin{array}{l}\text { Myelodysplastic } \\
\text { syndrome }\end{array}$ & Mild & $\begin{array}{l}\text { Marker not } \\
\text { detected }\end{array}$ & 3 & NA & Yes & No information & No information \\
\hline Patient 8 & $\begin{array}{l}\text { Myelodysplastic } \\
\text { syndrome }\end{array}$ & Mild & 14 & 28 & 28 & Yes & 101, week 21 & No information \\
\hline Median for patients 1-8 &. & .. & 5 & 7 & 10 & .. & .. & .. \\
\hline \multicolumn{9}{|l|}{ Patients 9-14 } \\
\hline Patient 9 & Aplastic anaemia & Moderate & 8 & Marker not detected & $>12$ & Not & 43, week 4 & Sepsis death $\dagger$ \\
\hline Patient 10 & Metastatic cancer & Moderate & $\begin{array}{l}\text { Marker not } \\
\text { detected }\end{array}$ & 6 & NA & Yes & No information & No information \\
\hline Patient 11 & Aplastic anaemia & Moderate & 4 & 10 & $>10$ & No† & 200, week 7 & Cardiac death $\dagger$ \\
\hline Patient 12 & Acute renal failure & Moderate & 3 & 11 & 11 & Yes & 148 , week 9 & Steroid reduction \\
\hline Patient 13 & $\begin{array}{l}\text { Non-Hodgkin } \\
\text { lymphoma }\end{array}$ & Moderate & 13 & 13 & $>43$ & No & No information & No information \\
\hline Patient 14 & $\begin{array}{l}\text { Acute myeloid } \\
\text { leukaemia }\end{array}$ & Moderate & 12 & 21 & 25 & Yes & 1380 , week 20 & No information \\
\hline Median for patients 9-14 & .. & & 8 & 11 & 18 & .. & .. & \\
\hline \multicolumn{9}{|l|}{ Patients 15-18 } \\
\hline Patient 15 & $\begin{array}{l}\text { Acute myeloid } \\
\text { leukaemia }\end{array}$ & High & 17 & 38 & $>40$ & No & Not elevated & Deceased \\
\hline Patient 16 & $\begin{array}{l}\text { Acute myeloid } \\
\text { leukaemia }\end{array}$ & High & 7 & Marker not detected & 16 & Yes & Not elevated & $\begin{array}{l}11 \text { weeks of } \\
\text { Ribavirin }\end{array}$ \\
\hline Patient 17 & Failed transplant & High & 7 & Marker not detected & $>10$ & No† & $295 \ddagger$, week 7 & Sepsis death $\dagger$ \\
\hline Patient 18 & $\begin{array}{l}\text { Multi organ } \\
\text { transplant }\end{array}$ & High & 11 & 37 & 44 & Yes & 40 , week 22 & $\begin{array}{l}\text { Reduction of drug } \\
\text { dose }\end{array}$ \\
\hline Median for patients $15-18$ & .. & .. & 9 & 37.5 & 30 & .. & .. & .. \\
\hline
\end{tabular}

two had returned to their country of origin. In no case did the clinical team judge that HEV had contributed to any illness or to death. Therefore, 43 patients were followed up (table 2).

Six patients (1-3, 6, 7, and 10) had serological markers of the recent development of antibody (seroconversion) when first tested at a median of 6 weeks (range 3-14 weeks) after transfusion (table 3). High concentrations of antiHEV IgG (sample/cutoff [S/CO] >20) were detected in all samples, IgM was detected in one sample (S/CO 1.2), and borderline IgM (S/CO 0.7-0.9) was detected in three samples. A further 12 recipients were viraemic at one or more timepoints in the post-transfusion period (table 3 ). Taking both groups together, the overall transmission rate was $42 \%$ (18 of 43 exposed patients), supported by the finding of sequences in each of the 12 viraemic recipients that were identical to sequences from the involved donors (figure 1). 25 recipients were judged to not have been infected, 16 of whom had no serological evidence of HEV infection at 16 weeks after transfusion and nine who were both seronegative and non-viraemic at 8 weeks or longer after transfusion.

The components associated with transmission of HEV to recipients are shown in table 2; red blood cells seemed to be the component least likely to transmit infection. HEV antibody was detected in four $(22 \%)$ of 18 donations associated with virus transmission and in $13(52 \%)$ of 25 donations not associated with 


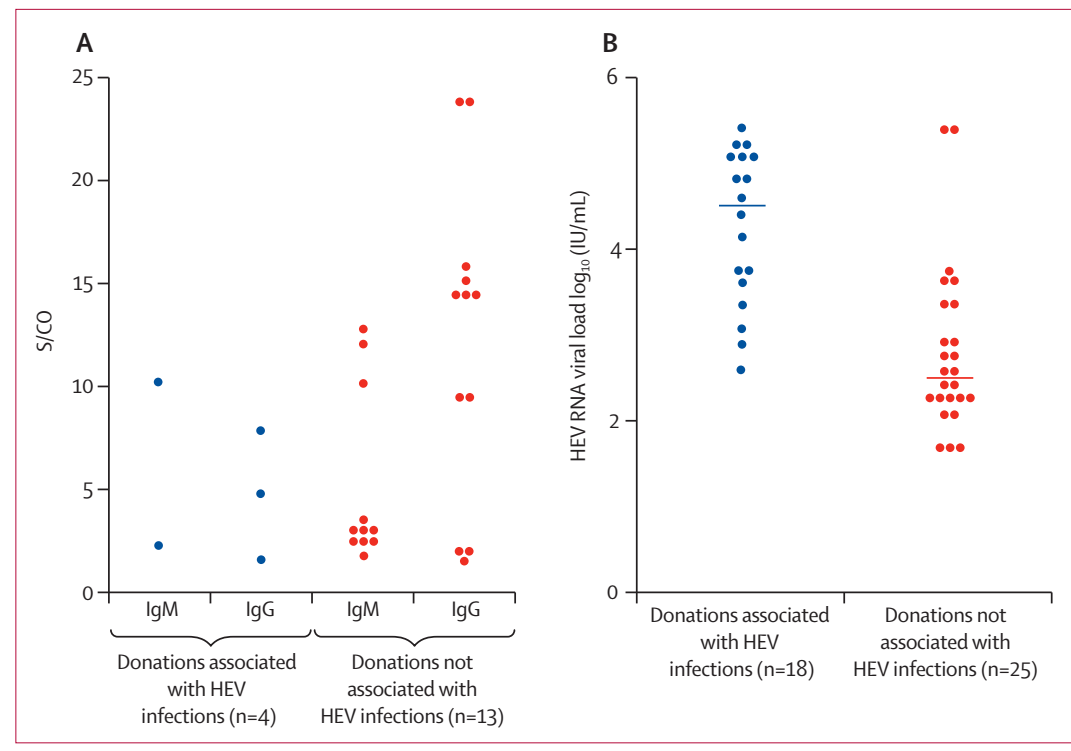

Figure 2: Data spread plot of HEV IgM and IgG antibody levels in donors whose components transmitted HEV compared with those that did not (A) and HEV RNA levels in donors whose components transmitted HEV compared with those that did not (B)

In (B), the bars indicate median viral load values for donations that were or were not associated with HEV infections (4.53 IU/mL [range $2.61-5.41$ ] vs $2.57 \mathrm{IU} / \mathrm{mL}$ [1.70-5.49], $\mathrm{p}<0.0001) . \mathrm{S} / \mathrm{CO}=$ sample/cutoff.

transmission. The antibody levels were much lower in the four donations that resulted in transmission than in the 13 that did not (figure 2A). The HEV viral load was about $1.5 \log _{10}$ higher in the donations that transmitted than in those that did not (figure 2B).

Follow-up of the infected recipients showed a varied response to infection, reflecting their overall clinical state and inferred degree of immunosuppression. The median times for seroconversion and duration of infection increased in patients as the degree of immunosuppression increased (table 3). Eight patients (1-8) were deemed to be immunocompetent or only mildly immunosuppressed (table 3). Five patients cleared their infection without having detectable viraemia, the other three recipients cleared their RNA in a median of 10 weeks (table 3). Six patients (9-14) with varying degrees of moderate immunosuppression had a longer median time of 11 weeks to seroconversion and a median duration of viraemia of 18 weeks (table 3 ). Four patients (15-18) were judged to be heavily immunosuppressed. In these patients, seroconversion was either very delayed (week 38 for patient 15 and week 37 for patient 18) or was not detected.

In three viraemic recipients, one moderately (patient 12) and two severely immunosuppressed (patients 16 and 18), an elective decision was made to induce viral clearance. In patient 12 , steroid dose reduction and withdrawal of additional immunosuppressive drugs 9 weeks after transfusion led to seroconversion and viral clearance over 3 weeks. In patient 18 , changes in immunosuppressive therapy coincided with the onset of seroconversion at 37 weeks and subsequent viral clearance from both stool and plasma. In patient 16 ,
2 weeks of ribavirin was given between cycles of chemotherapy at 12 weeks after transfusion and led to a 1000 times reduction in HEV RNA concentrations but not to clearance. Further ribavirin treatment starting at 19 weeks after transfusion led to viral clearance in the absence of a detectable antibody response.

Clinical hepatitis was reported in only one recipient (patient 4), whose indication for transfusion was a cardiac surgical procedure (table 3). 5 weeks after transfusion, the patient consulted with the family doctor and was confirmed to have hepatitis, associated with HEV seroconversion. Four other recipients (patients 8, 11, 12, and 14) had asymptomatic transaminitis coincident with seroconversion, which was triggered in patient 12 by a change in therapy. Transaminitis was marked in patient 14 in whom plasma alkaline phosphatase was also elevated for 1 week before the first development of anti-HEV antibodies. No infected patient was reported to have neurological disease.

\section{Discussion}

The prevalence of blood donations containing HEV RNA was higher than anticipated in the planning of the project. When projected across the country, and allowances are made for the duration of a detectable viraemia for 8 weeks, a prevalence of one in 2848 indicates that about 80000-100 000 acute HEV infections are likely to have occurred in England during the year of the study. This is close to the modelled estimate ${ }^{20}$ and shows a truly sizeable zoonosis, including both group 1 and group 2 viruses of genotype $3 \mathrm{HEV}^{7}$ which was also transmitted to the donors identified in this study (figure 1). Similar prevalences of viraemia have been reported in Sweden and Germany, ${ }^{21-23}$ suggesting that this zoonosis is also widespread across the European continent, further supported by a recently reported case of post-transfusion HEV in France (panel). ${ }^{24}$

The inevitable delay between donation and the identification of a viraemic donor meant that when recall of components was started, a high proportion of the short shelf-life components had already been transfused and most of the recalled units were inevitably of the longer shelf-life red cell and frozen components. This might have altered the profile of recipients towards those who were immunosuppressed and requiring platelet support.

Two linked variables in the donor plasma that were associated with transmission were the anti-HEV status of the donation and the level of virus in the plasma (figure 2A, 2B). Overall, donations containing antibody were less likely to transmit and, when they did, there was a trend for lower levels of anti-HEV to be associated with transmission. Donations associated with transmission had significantly higher levels of plasma RNA $(\mathrm{p}<0 \cdot 0001)$ than did those not associated with transmission, but overall viral RNA levels were ten times lower in viraemic donors than in the plasma of patients presenting with acute clinical hepatitis E (median $6 \cdot 2 \times 10^{4} \mathrm{IU} / \mathrm{ml}$, range 20 to 
$4.2 \times 10^{7}$; unpublished data). In this study it was not possible to ascertain the serological status of the recipient before transfusion because of the unavailability of samples.

The numbers of components in each category were insufficient for a robust attribution of transmissibility, though there is clearly a trend for those components that contain larger plasma volumes, principally fresh frozen plasma and platelet components, to transmit more readily. Despite this, in some instances apparently susceptible individuals who were challenged with components prepared from donors with high-level HEV viraemia did not become infected, raising the question of whether some people are innately resistant to infection or whether coincidental administration of antibodycontaining components from other donors might also have mitigated the risk of infection.

Table 3 shows that the immunological integrity of the host materially alters the time course of the posttransfusion infection. Increasing immunosuppression prolongs viraemia and delays seroconversion. Although eight of 12 viraemic recipients underwent seroconversion, coinciding in some with a biochemical transaminitis, seroconversion does not necessarily bring about clearance and can still be followed by longterm viraemia (patients 13 and 15). At the other end of this range, four heavily immunosuppressed patients either did not produce anti-HEV or had very delayed seroconversion and exhibited prolonged viraemia as described previously in recipients of solid organ transplants. ${ }^{16}$

What is of concern in this small series is that ten patients infected through transfused components seemed likely to be at the beginning of long-term persistence. Two patients (8 and 14) cleared viraemia spontaneously late after infection, four $(9,11,15$, and 17$)$ remained viraemic at time of their deaths, and four $(12,13,16$, and 18) were at risk of chronic liver disease and requiring continued monitoring and possible intervention. In three cases, the decision to attempt viral clearance was made. Indirect antiviral intervention with electively reduced immunosuppression led to seroconversion and viral clearance in two recipients (10 and 18). Direct antiviral intervention with ribavirin led to resolution of the infection without seroconversion in patient 16. The fourth patient (13) remains the only persistently infected recipient a year after transfusion.

Our findings confirm the potential danger of transfusion-transmitted $\mathrm{HEV}$ in the transplant and haemoncology settings but also the susceptibility of this persistent infection to immune clearance. Persistent infection might be more of a hazard for recipients of solid organ transplant in whom the immunosuppression is unremitting than for recipients of stem cell transplantation in which immune recovery might be expected. Based on the finding of little acute morbidity, there is no indication to alter previously optimised treatment pathways for patients who have been exposed or infected with HEV. Two-thirds of patients are likely to clear

\section{Panel: Research in context}

\section{Systematic review}

We searched MedLine for articles published in the 7 years up to December, 2013, on the topic of HEV and blood safety. We used a range of keywords including "hepatitis E", "HEV", "blood safety", "transmission", "blood donors", and "recipients". In the past 10 years hepatitis E virus (HEV) has been increasingly recognised as a zoonotic infection in highincome countries where it was previously thought to be an imported infection. Current infection in blood donors and a small number of post-transfusion cases from some countries indicate a potential for transmission by transfusion. No systematic analysis of transmission rates and clinical effect of transfusion-transmitted HEV exists in published literature.

\section{Interpretation}

We have defined the prevalence of viraemic donors and transmission to recipients. Spontaneous clearance without clinical disease was common, despite delayed seroconversion, and resulting acute illness was rare. Our data are from the first reported systematic study of HEV transmission from donors infected by an extensive but largely non-apparent zoonosis in England. On a clinical basis alone, the resulting minimal burden of disease does not signal a pressing need for donation screening at this time.

infection spontaneously, and when long-term persistence develops intervention can be undertaken electively. ${ }^{25}$ Immune recovery is the desired outcome in many haematological situations and this alone might well bring about viral clearance that might also be associated, like seroconversion, with an illness during viral clearance. ${ }^{26}$

Since HEV infection transmits through transfusion and the incidence of acute infection in donors from the southeast of England is high, about $1200 \mathrm{HEV-containing}$ components are likely to be released for transfusion purposes each year in England. Most infections will not be identifiable through any acute illness in the immediate post-transfusion period but might present much later at the time of immune reconstitution or as a manifestation of long-term chronic liver disease, especially in solid organ transplants when an association with transfusion might not be made. One way of mitigating unfavourable outcomes would be to introduce routine yearly screening for persistent $\mathrm{HEV}$ infection in all transplant patients with an option to treat those who are chronically infected independent of the route of infection.

Setting aside this option, what would be a proportionate response to this zoonosis? Is it possible to deal with the source of infection that is likely to be foods containing pork, ${ }^{8}$ perhaps advising patients at risk to modify their diet as is done for listeria? A societal change reverting to the old principle of extended cooking of pork would not fit with the tendency to consume it lightly cooked now that trichinosis is no longer a perceived hazard. ${ }^{27}$ Addressing animal husbandry and determining how to 
control HEV in pig herds remains a possibility, although an easily transmissible enteric agent like $\mathrm{HEV}^{28}$ will be more difficult to control than trichinella. Alternatively, screening of blood donations, at substantial cost, on the basis of reducing the risk of long-term infection, would remove the bulk of the transfusion hazard but still allow the dietary risk to transplant patients; this issue was addressed in Toulouse, France, by the removal of the figatelu liver sausage from the hospital diet. Nevertheless, every donor exposure in England and Wales will increase the likelihood of recipient infection by one in 3000 , and if a recipient in 1 year of treatment were to be exposed to components from 20 donors the accumulated yearly risk from transfusion would be one in 150 compared with a dietary risk of one in 500-1000, modelled on the yearly seroconversion rate of $0 \cdot 1-0 \cdot 2 \%$. Our experience in this study, however, indicates that the burden of harm engendered by HEV acquisition through transfusion is very slight and from a clinical perspective alone there seems no pressing need to move rapidly with the introduction of donation screening. The broader issues of HEV and blood safety, including the need for donation screening, ${ }^{29}$ will be addressed in the UK later this summer after the recent commissioning of a short-life expert committee of the UK Departments of Health Advisory Committee on the Safety of Blood, Tissues and Organs to consider these matters within the context of a financially constrained health service.

The magnitude of the current zoonosis in Europe is shown by both more cases of hepatitis $\mathrm{E}$ being reported for England in 2012 than in 2011, and an increase in prevalence of HEV antibody in young Dutch blood donors (Zaaijer H, Sanquin Blood Supply Foundation, personal communication). It should be borne in mind that HEV disease in England and Wales shows considerable temporal variation, and though the magnitude of the risk now possibly justifies intervention ${ }^{30}$ it is unlikely that the high frequency of acute infection will be maintained indefinitely; this provides another complication in the decision of an appropriate response to this interesting and rather unexpected transfusionassociated infection in the UK.

\section{Contributors}

RST, SI, KIT, and PEH designed the study. AK managed and coordinated the collection and subsequent pooling of blood samples used in this study. PEH and IUL oversaw the follow-up of the recipients. SRB, KR, ITRK, JT, IUL, and PEH contacted the clinical teams or family doctors of the recipients and coordinated the follow-up of these patients. RST, $\mathrm{PEH}$, and IUL worked with the clinical teams in the management of the recipients. RB, SD, BH, PP, and JP undertook all the laboratory work for this project and were all involved in the analysis of the generated data. SI and RST oversaw the delivery and interpretation of the laboratory aspects for this study. KT was responsible for the overall management of the study and also for data handling and storage. PEH, SI, and RST wrote the manuscript. PEH and SI contributed equally to the preparation of the manuscript. All authors reviewed and commented on the text.

Declaration of interests

We declare no competing interests.

\section{Acknowledgments}

This study was jointly funded internally by Public Health England and the NHSBT. We thank the members of National Transfusion Microbiology Office and Transfusion Microbiology Surveillance, particularly Gill Rayfield and Raji Salker; members of the National Transfusion Microbiology Reference Laboratory including Alex Boateng, Ruwanika Kothalawala, and Nazow Azim; Sam Lattimore at the Centre for Infectious Disease Surveillance and Control, Public Health England for valuable statistical advice; colleagues in the joint Blood Borne Virus Unit Public Health England for help in the running of this study and participation in steering group meetings; NHSBT donors for their enthusiastic contribution to the study; NHSBT Filton for collation and dispatch of donor samples to Colindale; National Health Service staff in both trust and community services for their sensitive handling of potentially difficult situations engendered by the Look Back requirement, and the members of the data monitoring committee for their enduring advice.

\section{References}

1 Khuroo MS. Study of an epidemic of non-A, non-B hepatitis. Possibility of another human hepatitis virus distinct from post-transfusion non-A, non-B type. Am J Med 1980; 68: 818-24

2 Balayan MS, Andjaparidze AG, Savinskaya SS, et al. Evidence for a virus in non-A, non-B hepatitis transmitted via the fecal-oral route. Intervirology 1983; 20: 23-31.

3 Balayan MS, Usmanov RK, Zamyatina NA, Djumalieva DI, Karas FR. Brief report: experimental hepatitis E infection in domestic pigs. J Med Virol 1990; 32: 58-59.

4 Reyes GR, Purdy MA, Kim JP, et al. Isolation of a cDNA from the virus responsible for enterically transmitted non-A, non-B hepatitis. Science 1990; 247: 1335-39.

5 Ijaz S, Arnold E, Banks M, et al. Non-travel-associated hepatitis E in England and Wales: demographic, clinical, and molecular epidemiological characteristics. J Infect Dis 2005; 192: 1166-72.

6 Lewis HC, Boisson S, Ijaz S, et al. Hepatitis E in England and Wales. Emerg Infect Dis 2008; 14: 165-67.

7 Ijaz S, Said B, Boxall E, Smit E, Morgan D, Tedder RS. Indigenous Hepatitis E in England and Wales from 2003 to 2012: Evidence of an emerging novel phylotype of viruses. J Infect Dis 2014; 209: 1212-18.

8 Said B, Ijaz S, Chand MA, Kafatos G, Tedder R, Morgan D. Hepatitis E virus in England and Wales: indigenous infection is associated with the consumption of processed pork products. Epidemiol Infect 2014; 142: 1467-75.

9 Colson P, Borentain P, Queyriaux B, et al. Pig liver sausage as a source of hepatitis E virus transmission to humans. J Infect Dis 2010; 202: 825-34

10 Tei S, Kitajima N, Takahashi K, Mishiro S. Zoonotic transmission of hepatitis E virus from deer to human beings. Lancet 2003; 362: 371-73.

11 Masuda J, Yano K, Tamada Y, et al. Acute hepatitis E of a man who consumed wild boar meat prior to the onset of illness in Nagasaki, Japan. Hepatol Res 2005; 31: 178-83.

12 Boxall E, Herborn A, Kochethu G, et al. Transfusion-transmitted hepatitis E in a 'nonhyperendemic' country. Transfus Med 2006; 16: 79-83.

13 Ijaz S, Szypulska R, Tettmar KI, Kitchen A, Tedder RS. Detection of hepatitis E virus RNA in plasma mini-pools from blood donors in England. Vox sanguinis 2012; 102: 272

14 Cleland A, Smith L, Crossan C, et al. Hepatitis E virus in Scottish blood donors. Vox sanguinis 2013; 105: 283-89.

15 Beale MA, Tettmar K, Szypulska R, Tedder RS, Ijaz S. Is there evidence of recent hepatitis E virus infection in English and North Welsh blood donors? Vox sanguinis 2011; 100: 340-42.

16 Kamar N, Selves J, Mansuy JM, et al. Hepatitis E virus and chronic hepatitis in organ-transplant recipients. N Engl J Med 2008; 358: 811-17.

17 Dalton HR, Bendall RP, Keane FE, Tedder RS, Ijaz S. Persisten carriage of hepatitis E virus in patients with HIV infection. N Engl J Med 2009; 361: 1025-27.

18 Jagjit Singh GK, Ijaz S, Rockwood N, et al. Chronic Hepatitis E as a cause for cryptogenic cirrhosis in HIV. J Infect 2013; 66: 103-06.

19 Garson JA, Ferns RB, Grant PR, et al. Minor groove binder modification of widely used TaqMan probe for hepatitis $\mathrm{E}$ virus reduces risk of false negative real-time PCR results. J Virol Methods 2012; 186: 157-60. 
20 Ijaz S, Vyse AJ, Morgan D, Pebody RG, Tedder RS, Brown D. Indigenous hepatitis $\mathrm{E}$ virus infection in England: more common than it seems. J Clin Virol 2009; 44: 272-76.

21 Baylis SA, Gartner T, Nick S, Ovemyr J, Blumel J. Occurrence of hepatitis E virus RNA in plasma donations from Sweden, Germany and the United States. Vox Sang 2012; 103: 89-90.

22 Corman VM, Drexler JF, Eckerle I, Roth WK, Drosten C, Eis-Hubinger AM. Zoonotic hepatitis E virus strains in German blood donors. Vox Sang 2013; 104: 179-80.

23 Juhl D, Baylis SA, Blumel J, Gorg S, Hennig H. Seroprevalence and incidence of hepatitis E virus infection in German blood donors. Transfusion 2014; 54: 49-56.

24 Coilly A, Haim-Boukobza S, Roche B, et al. Posttransplantation hepatitis E: transfusion-transmitted hepatitis rising from the ashes. Transplantation 2013; 96: e4-6.

25 Kamar N, Rostaing L, Izopet J. Hepatitis E virus infection in immunosuppressed patients: natural history and therapy. Semin Liver Dis 2013; 33: 62-70.
26 Andersson MI, Preiser W, Maponga TG, et al. Immune reconstitution hepatitis $\mathrm{E}$ : a neglected complication of antiretroviral therapy in Africa? AIDS 2013; 27: 487-89.

27 Gottstein B, Pozio E, Nockler K. Epidemiology, diagnosis, treatment, and control of trichinellosis. Clin Microbiol Rev 2009; 22: $127-45$.

28 Casas M, Pina S, de Deus N, Peralta B, Martin M, Segales J. Pigs orally inoculated with swine hepatitis E virus are able to infect contact sentinels. Vet Microbiol 2009; 138: 78-84.

29 Feray C, Pawlotsky JM, Roque-Afonso AM, Samuel D, Dhumeaux D. Should we screen blood products for hepatitis E virus RNA? Lancet 2014; 383: 218.

30 Versluis J, Pas SD, Agteresch HJ, et al. Hepatitis E virus: an underestimated opportunistic pathogen in recipients of allogeneic hematopoietic stem cell transplantation. Blood 2013; 122: 1079-86. 